\title{
EVIDENCIAÇÃO AMBIENTAL: UM ESTUDO DE CASO EM UMA INDÚSTRIA POTENCIALMENTE POLUIDORA
}

\author{
Ilaci Pavesi ${ }^{1}$, Elise Soerger Zaro ${ }^{1}$, Rogerio João Lunkes ${ }^{1}$, Fabricia Silva Rosa ${ }^{2}$ \\ ${ }^{1}$ Universidade Federal de Santa Catarina - UFSC \\ ${ }^{2}$ Fundação Universidade Regional de Blumenau - FURB \\ ilacip@terra.com.br, elise sz@yahoo.com, e rogeriolunkes@hotmail.com, \\ fabriciarosa@hotmail.com
}

\begin{abstract}
Resumo
Este estudo objetiva avaliar o desempenho da evidenciação ambiental de uma empresa do setor industrial do estado de Santa Catarina considerada potencialmente poluidora. Neste intuito, adotou-se uma pesquisa do tipo estudo de caso, de natureza descritiva, com abordagem do problema qualitativa e documental quanto aos procedimentos técnicos. Os dados foram coletados no Relatório de Sustentabilidade referente ao exercício de 2013 divulgado pela empresa. Para atingir este objetivo aplicou-se o modelo de avaliação de desempenho Environmental Disclosure Evaluation(EDE), composto por 103 critérios distribuídos em quatro clusters: (i) gestão ambiental, (ii) consumo de recursos naturais; (iii) emissões, efluentes, resíduos e impactos; e (iv) conformidade legal e aspectos financeiros. O modelo é baseado no Global Reporting Initiative (GRI) e criado a partir da Metodologia Multicritério de Apoio a Decisão Construtivista (MCDAC). Como resultado global, verificou-se que a média do índice de desempenho alcançado pela empresa foi de 31,23 pontos, representando considerado "moderado". Observou-se um maior comprometimento da empresa com informações para as áreas de gestão ambiental, consumo de recursos naturais, emissão e resíduos, itens avaliados com desempenho "forte/moderado". Constatou-se um desempenho "fraco" para os critérios efluentes líquidos, produtos e transporte; e "nulo" para os itens biodiversidade e conformidade legal.
\end{abstract}

Palavras-chave:Evidenciação Ambiental. Relatório de Sustentabilidade. Avaliação de Desempenho.

\section{ENVIRONMENTAL DISCLOSURE: A STUDY OF SANTA CATARINA STATE POTENTIALLY POLLUTING}

\begin{abstract}
This study aims to evaluate the environmental performance of a potentially polluting industrial company's disclosure of the state of Santa Catarina. To achieve this goal, we adopted a research case study, descriptive in nature type, with qualitative and documentary approach to problem regarding the technical procedures. Data were collected in the 2013 Sustainability Report of the company. It was applied the model Environmental Disclosure Evaluation (EDE), consisting of 103 criteria divided into four clusters: (i) environmental management, (ii) consumption of natural resources; (iii) emissions, effluents, waste and impacts; and (iv) legal compliance and financial aspects. The model is based on the Global Reporting Initiative (GRI) and created from the Multicriteria Methodology for Decision Support Constructivist (MCDA-C). As an overall result, it was found that the average rate performance achieved by the company was 31.23 points representing considered "moderate." There was a greater commitment of the company with information on the areas of environmental management, natural resource consumption, emissions and waste, items valued with "strong/moderate" performance. It found a "low"
\end{abstract}




\section{REAVI}

Universidade do Estado de Santa Catarina

Centro de Educação Superior do Alto Vale do Itajaí

performance criteria for wastewater, and transportation products; and "null" for biodiversity and legal compliance items.

Keywords: Environmental Disclosure. Sustainability Report.Performance Assessment.

\section{Introdução}

A preocupação com questões sobre a sustentabilidade perpassa discussões internacionais como a Conferência de Estocolmo, em 1972, divulgação do Relatório Brundtland, em 1989, Rio 92, em 1992 e Rio +20, em 2012, a tomada de consciência da população em relação à limitação dos recursos naturais, prática dos direitos humanos, erradicação da pobreza, entre outros tópicos polêmicos(BELLEN, VAN, 2005; BORGES; TACHIBANA, 2005; NASCIMENTO, 2012). Essas discussões, dentre outros fatores influenciaram as corporações a se engajarem nessas discussões a apresentarem práticas mais sustentáveis.

Neste sentido, Schaltegger e Burritt(2010) destacam que a implementação de controles ligados à sustentabilidade é motivada por questões internas a organização e benefícios obtidos com o controle e gerenciamento de informações concernentes ao meio ambiente e a sociedade, porém salientam seis variáveis que a literatura indica como motivadores para a adoção dessas práticas: 1) Obtenção de informações para a evidenciação ambiental; 2) Mimetismo e da pressão indústria; 3) Pressões legislativas e dos stakeholders e manutenção de licenças de operações; 4) Política da empresa; 5) Responsabilidade corporativa e razões éticas; 6) Gerenciamento da empresa com enfoque na sustentabilidade.

Diante da evolução das discussões sobre sustentabilidade em um contexto global e o engajamento das empresas nesse contexto, surgiram diversas ferramentas que auxiliam na gestão dos recursos de forma responsável(CORTEZ et al., 2014). No estudo realizado por Cortez et al. (2014) foi identificado que dentre as ferramentas analisadas as diretrizes do Global Reporting Initiative (GRI)solicitam das empresas umamaior evidenciação. As diretrizes do GRI auxiliam as organizações na divulgação das informações sobre sustentabilidade, porém também auxiliam na sua própria avaliação através de um conjunto de indicadores de desempenho financeiro, ambiental, social e de governança.

Com base nas diretrizes do GRI e a partir da Metodologia Multicritério de Apoio a Decisão Construtivista (MCDA-C) desenvolveu-se o modelo Environmental Disclosure Evaluation (EDE) (CRESPO SOLER, RIPOLL FELIU, ROSA e LUNKES, 2011). O processo estruturado da metodologia do modelo EDE permite identificar, medir, integrar, apresentar forma de construir diagnóstico e ações de melhoria. Assim, um modelo de avaliação de desempenho deve funcionar como uma ferramenta que permita a avaliação do desempenho do comprometimento dos processos operacionais e de gestão das empresas produzindo informações úteis aos seus usuários.

Diante deste contexto, esta pesquisa pretende responder a seguinte questão: como estão sendo evidenciadas as informações ambientais de uma indústria de Santa Catarina potencialmente poluidora? Para responder a esta pergunta de pesquisa, tem-se como objetivo: avaliar o desempenho da evidenciação ambiental de uma indústria de compressores catarinense potencialmente poluidora.

As empresas que causam maiores danos ambientais sofrem maior pressão para adotar ações mais sustentáveis e consequentemente divulgar essas informações. No Brasil a Lei $\mathrm{n}^{\circ}$ 6.938/1981, alterada pela Lei $\mathrm{n}^{\mathbf{0}} 10.165 / 2000$, que dispõe sobre a política nacional do meio ambiente, identificou as atividades potencialmente poluidoras e utilizadoras de recursos ambientais, portanto justifica-se a utilização de uma empresa classificada como potencialmente poluidora como objeto do estudo. Formatação geral 


\section{REAVI}

Universidade do Estado de Santa Catarina

Centro de Educação Superior do Alto Vale do Itajaí

\section{Fundamentação teórica}

Diversos fatores influenciam as empresas a buscar práticas mais sustentáveis, 8 fatores foram destacados pelo International Federation of Accountants - IFAC(2011) como os mais importantes: foco nos consumidores e públicos de interesse; efetividade das estratégias e liderança; integração da governança, risco e controle; inovação e adaptabilidade; gestão financeira; gerenciamento de pessoas e talentos; execução das estratégias; e comunicação transparente e efetiva. $O$ último fator citado, que concerne a evidenciação de informações sobre a empresa, sua gestão e prospecções de maneira a atingir seus públicos interessados, movem as empresas a melhoria continua e a transformação ao longo do tempo de suas divulgações. Segundo Tinoco e Kraemer(2004) o objetivo da evidenciação é a divulgação fidedigna de informações concernentes às dimensões econômica, financeira, social e ambiental das entidades, tendo como público alvo os parceiros sociais e os stakeholders, sendo contempladas em demonstrativos financeiros ou outras formas de divulgação.

É possível perceber que a transparência das informações não financeiras é uma preocupação da administração das empresas, Schaltegger e Burritt (2010)esclarecem que a contabilidade ambiental é uma ferramenta que demonstra a preocupação ambiental e auxiliar na coleta de dados para a comunicação e preparação de relatórios e complementam com uma critica relativa a falta de prioridade no efetivo desempenho sustentável.

A evidenciação ambiental deve suprir as necessidades de informações demandas pelas partes interessadas, para tanto o sistema de gestão ambiental de uma organização deve ser estruturado de forma a fornecer informações relativas aos eventos e transações ambientais, que permitam a tomada de decisão. A comunicação deve apresentar o grau de detalhamento adequado ao valor e natureza dos eventos (BRAGA, 2007).

Existem diferentes abordagens que explicam as motivações que levaram as companhias a evidenciação de suas práticas e eventos ambientais. Nikolaeva e Bicho(2011) apresentaram algumas das principais motivações e seus efeitos sobre a responsabilidade corporativa, conforme se verifica no Quadro 1:

\begin{tabular}{|c|c|}
\hline Teoria & Implicações para a evidenciação da sustentabilidade \\
\hline $\begin{array}{l}\text { Economia do custo da } \\
\text { transação }\end{array}$ & $\begin{array}{l}\text { As empresas irão se engajar nos relatórios de sustentabilidade quando estas } \\
\text { possuam um claro incentivo econômico para fazê-lo. Menores custos de } \\
\text { evidenciação ambiental aumentam a probabilidade de adoção. }\end{array}$ \\
\hline Teoria da agência & $\begin{array}{l}\text { A evidenciação da sustentabilidade pode ser inadequada para enfrentar às } \\
\text { preocupações conflitantes do principal. }\end{array}$ \\
\hline Teoria institucional & $\begin{array}{l}\text { As empresas podem se tornar mais legitimas adequando nas indústrias } \\
\text { emergentes as tendências da evidenciação ambiental. }\end{array}$ \\
\hline Ecologia organizacional & $\begin{array}{l}\text { A evidenciação da sustentabilidade estará na visão das nas novas organizações à } \\
\text { medida que estas se adequarem mais ao triple bottom line. }\end{array}$ \\
\hline $\begin{array}{l}\text { Teoria da dependência de } \\
\text { recursos }\end{array}$ & $\begin{array}{l}\text { A evidenciação da sustentabilidade tal vez seja o resultado das influencias do } \\
\text { poder antes que considerações econômicas. Os relatórios de sustentabilidade } \\
\text { poderiam implicar menos regulação de agências do governo. }\end{array}$ \\
\hline $\begin{array}{l}\text { Visão da firma baseada nos } \\
\text { recursos }\end{array}$ & A evidenciação ambiental pode fornecer uma vantagem competitiva. \\
\hline $\begin{array}{l}\text { Teoria dos escalões } \\
\text { superiores }\end{array}$ & $\begin{array}{l}\text { A evidenciação da sustentabilidade é uma função da gestão de fundo e vieses } \\
\text { cognitivos. }\end{array}$ \\
\hline Teoria das redes sociais & $\begin{array}{l}\text { Os relatórios de sustentabilidade se espalham através das redes de empresas } \\
\text { interconectadas. }\end{array}$ \\
\hline Teoria dos sinais & $\begin{array}{l}\text { A evidenciação da sustentabilidade pode ser usada para sinalizar o tipo de } \\
\text { sustentabilidade da empresa aos stakeholders. }\end{array}$ \\
\hline
\end{tabular}

Quadro 1 - Teorias organizacionais e a evidenciação da sustentabilidade (Nikolaeva e Bicho, 2011) 


\section{REAVI}

Universidade do Estado de Santa Catarina

Centro de Educação Superior do Alto Vale do Itajaí

A evidenciação é realizada pelos relatórios financeiros convencionais e com publicação obrigatória, constando informações em notas explicativas, relatório da administração e relatórios de sustentabilidade(CALIXTO, 2009; BEUREN et al., 2010; SOARES et al., 2012), também existem informações nos formulários de referência.

As divulgações de informações sobre a sustentabilidade das empresas evoluiu ao longo do tempo, mudando seu formato e enfoque, até os anos 1990, as corporações davam maior enfoque na divulgação de informações ambientais, apenas após a divulgação das diretrizes da GRI Global Reporting Initiative para a elaboração do relato integrado houve uma intensificação da divulgação de informações financeiras, sociais e ambientais(KPMG, 2005; DAUB, 2007; GRI, 2014).

O GRI foi fundado em Boston, no ano de 1997, a partir de uma iniciativa conjunta da Coalition for Environmentally Responsible Economies (CERES) e o Instituto Tellis, o qual se caracteriza como um grupo de trabalho multi-stakeholders com o objetivo decriar uma estrutura internacional que auxilie as organizações a elaborar suas divulgações de sustentabilidade a partir do conceito de Triple Bottom Line, assim evidenciando sua atuação e performance econômica, social e ambiental (GRI, 2014). A discussão sobre Triple Bottom Line (TBL) foi iniciado por Elkington, que advogava que para atingir o desenvolvimento sustentável é necessário analisar o resultado financeiro, ambiental e social e as organizações devem buscar equilibrar os ganhos e perdas em todas essas dimensões(ELKINGTON, 2006; OWEN, 2013).

As diretrizes do GRI visam orientar as empresas sobre princípios, conceitos e elementos de conteúdo que devem ser divulgados. Segundo Daub(2007) um relatório de sustentabilidade deve conter as estratégias, riscos e oportunidades atinentes a sustentabilidade corporativa, as informações podem ser apresentadas de forma quantitativa e qualitativa ou ambas, de forma a evidenciar de forma clara e transparente o desempenho da organização e de que forma seu sistema de gestão gera valor nas perspectivas econômica, social e ambiental.

As diretrizes do GRI também podem auxiliar no planejamento, execução e avaliação das empresas, fornecendo informações para o gerenciamento dos recursos nas três dimensões. As diretrizes GRI são consideradas uma das ferramentas de responsabilidade corporativa mais completa e difundida para a comunicação, de forma voluntária, do desempenho social, ambiental, financeiro e de governança corporativa das organizações, que visa medir, divulgar e prestar contas para stakeholders da performance organizacional visando o desenvolvimento sustentável (GRI, 2011; GURVITSH; SIDOROVA, 2012).

Um estudo realizado periodicamente pela KPMG ajuda a suportar a afirmação acima de que as diretrizes do GRI são amplamente difundidas, em 2008, identificaram que $62 \%$ das 250 maiores empresas do mundo (listadas pela Fortune Global 500) que elaboraram relatórios de responsabilidade corporativa, o fizeram de acordo com essas diretrizes, em 2011 esse número elevou-se para $80 \%$ das empresas (KPMG, 2008, 2011). Outra evidência é a quantidade de documentos indexados na base de dados do (GRI - GLOBAL REPORTING INITIATIVE, 2014a) passando de 148 relatórios em 2002, a 739 relatórios em 2007 e atingindo 3.695 relatórios referentes ao ano de 2012.

As diretrizes do GRI propõem conceitos, princípios e principalmente, um conjunto de indicadores que se propõe a avaliar o desempenho das empresas nas dimensões ambiental, social e financeira. A avaliação de desempenho é o processo de gestão utilizado para construir, fixar e disseminar conhecimentos por meio da identificação, organização, mensuração e integração dos aspectos, de um determinado contexto, julgados relevantes para medir e gerenciar o desempenho daquilo que se deseje monitorar e/ou aperfeiçoar (ENSSLIN, L., DUTRA e ENSSLIN, S., 2000).

\section{Metodologia}




\section{REAVI}

Universidade do Estado de Santa Catarina

Centro de Educação Superior do Alto Vale do Itajaí

Nesta seção apresentam-se os procedimentos metodológicos utilizados para o enquadramento do estudo e o processo de seleção e análise dos resultados. A metodologia da pesquisa é descritiva quanto à natureza do objetivo, documental quanto aos procedimentos técnicos, aplicada no que tange aos resultados, os dados são secundários (Richardson, 2008) uma vez que se faz análise de conteúdo do Relatório de Sustentabilidade do ano de 2013. Quanto ao tipo de pesquisa trata-se de um estudo de caso (Yin, 2005) em uma indústria fabricante de compressores herméticos para refrigeradores do estado de Santa Catarina.

\subsection{Enquadramento metodológico}

\begin{tabular}{|l|l|l|}
\hline Aspectos & Referências & Objeto ou Objetivo \\
\hline Natureza do objetivo & $\begin{array}{l}\text { Descritiva (RICHARDSON, } \\
\text { 2008; GIL, 1995) }\end{array}$ & $\begin{array}{l}\text { Buscar identificar informações sobre a } \\
\text { evidenciação ambiental a partir da revisão da } \\
\text { literatura da pesquisa e com a utilização de técnicas } \\
\text { padronizadas de coleta de dados e observação } \\
\text { sistemática. }\end{array}$ \\
\hline Procedimentos técnicos & $\begin{array}{l}\text { Documental } \\
\text { (RICHARDSON, 2008) }\end{array}$ & $\begin{array}{l}\text { Análise do relatório de sustentabilidade } \\
\text { disponibilizado pela empresa. }\end{array}$ \\
\hline Tipo da pesquisa & $\begin{array}{l}\text { Estudo de Caso } \\
\text { (YIN, 2005) }\end{array}$ & $\begin{array}{l}\text { Contribuir para a compreensão do fenômeno } \\
\text { organizacionale social da evidenciação ambiental. }\end{array}$ \\
\hline Coleta de dados & $\begin{array}{l}\text { Dados secundários } \\
\text { RICHARDSON, 2008) }\end{array}$ & $\begin{array}{l}\text { Para coleta das informações ambientais utilizou- } \\
\text { se re ratório de sustentabilidade do ano de } \\
\text { 2013publicado pela empresa em seu site } \\
\text { institucional. }\end{array}$ \\
\hline $\begin{array}{l}\text { Abordagem do } \\
\text { problema }\end{array}$ & $\begin{array}{l}\text { Qualitativa (RICHARDSON, } \\
\text { 2008) } \\
\text { comunidade científica; e identificar como a } \\
\text { empresa pesquisada evidenciainformações } \\
\text { ambientais no relatório de sustentabilidade. }\end{array}$ \\
\hline Resultados & $\begin{array}{l}\text { Aplicada (RICHARDSON, } \\
\text { 2008) }\end{array}$ & $\begin{array}{l}\text { Gerar conhecimento sobre a evidenciação } \\
\text { ambiental, por meio de um referencial teórico sobre } \\
\text { o assunto de um Estudo de Caso. }\end{array}$ \\
\hline
\end{tabular}

Quadro 2 - Enquadramento metodológico da pesquisa

A metodologia da pesquisa é descritiva, os dados são secundários, uma vez que se faz análise de conteúdo no Relatório de Sustentabilidade do ano de 2013. Trata-se de um estudo de caso em uma empresa do setor industrial do estado de Santa Catarina.

O setor selecionado para a pesquisa justifica-se por fazer parte da cadeia produtiva da fabricação de refrigeradores, bens cujo consumo vem sendo amplamente incentivado por políticas governamentais através de subsídios para aquisição de eletrodomésticos da linha branca.

A empresa pesquisada tem capacidade produtiva superior a 30 milhões de compressores ao ano, emprega cerca de 10 mil colaboradores em seis países (Brasil, China, Itália, Eslováquia, Estados Unidos e México). É selecionada por ser líder mundial na fabricação de compressores herméticos para refrigeração, ser catarinense e por pertencer ao segmento potencialmente poluidor.

O modelo escolhido para a análise de conteúdo do Relatório de Sustentabilidade é o EDEEnvironmental Disclosure Evaluation (Crespo et al, 2011), modelo que permite identificar, medir, integrar, apresentar forma de construir diagnóstico e ações de melhoria.

\subsection{O modelo EDE}




\section{REAVI}

Universidade do Estado de Santa Catarina

Centro de Educação Superior do Alto Vale do Itajaí

O Modelo EDE é fundamentado nas diretrizes do GRI e na Metodologia MCDA-C Metodologia Multicritério de Apoio à Decisão Construtivista (ENSSLIN, MONTIBELLER e NORONHA, 2001). A motivação pela escolha do modelo EDE é a de que permite avaliar o desempenho de 103 critérios organizados em quatro áreas: Gestão ambiental; Consumo de Recursos Naturais; Emissões, Efluente, Resíduos e Impactos; e Conformidade Legal e Aspectos Financeiros, conforme Figura 1.

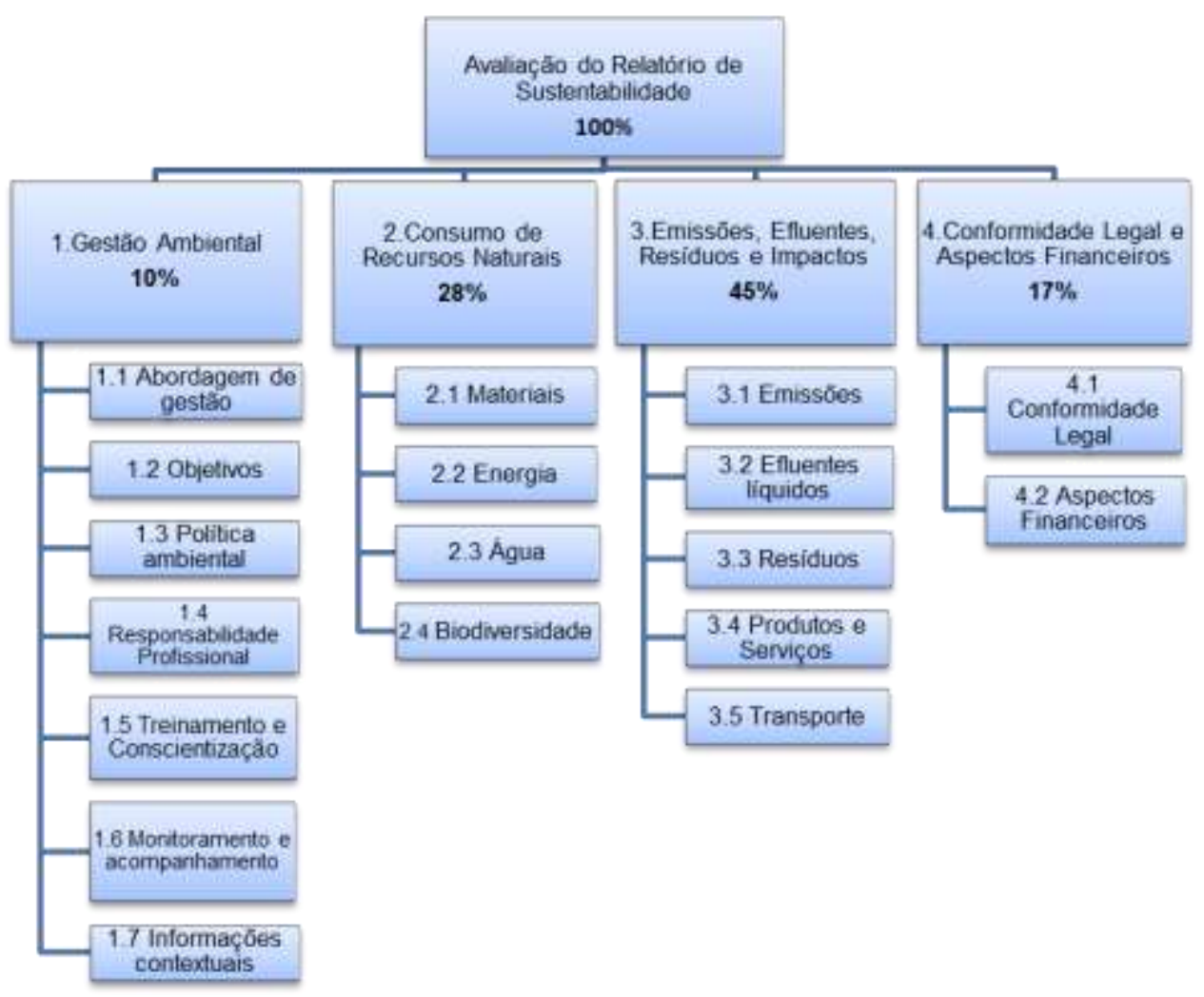

Figura 1: Modelo de avaliação das informações ambientais no Relatório de Sustentabilidade (adaptado de Crespo Soler et al.,(2011).

Cada um desses critérios e seus subcritérios são mensurados por meio de escalas, como exemplifica a Figura 2.

De acordo com Crespo Soler et al (2011),"’a avaliação global das alternativas é calculada por meio da equação de agregação aditiva, $\mathrm{V}(\mathrm{a})=\mathrm{w} 1{ }^{*} \mathrm{v} 1(\mathrm{a})+\mathrm{w} 2{ }^{*} \mathrm{v} 2(\mathrm{a})+\mathrm{w} 3{ }^{*} \mathrm{v} 3(\mathrm{a})+\ldots . . \mathrm{wn}{ }^{*} \mathrm{wn}(\mathrm{a})$. $\mathrm{V}(\mathrm{a})=$ Valor Global da Ação a; v1(a), v2(a), ... vn(a) = Valor parcial da ação a nos critérios 1, 2, $3, \ldots, n ; w 1(a)$, w2(a)... wn(a) = Taxas de substituição dos critérios $1,2,3, \ldots, n ; n=$ numero de critérios do modelo." 


\section{REAVI}

Universidade do Estado de Santa Catarina

Centro de Educação Superior do Alto Vale do Itajaí
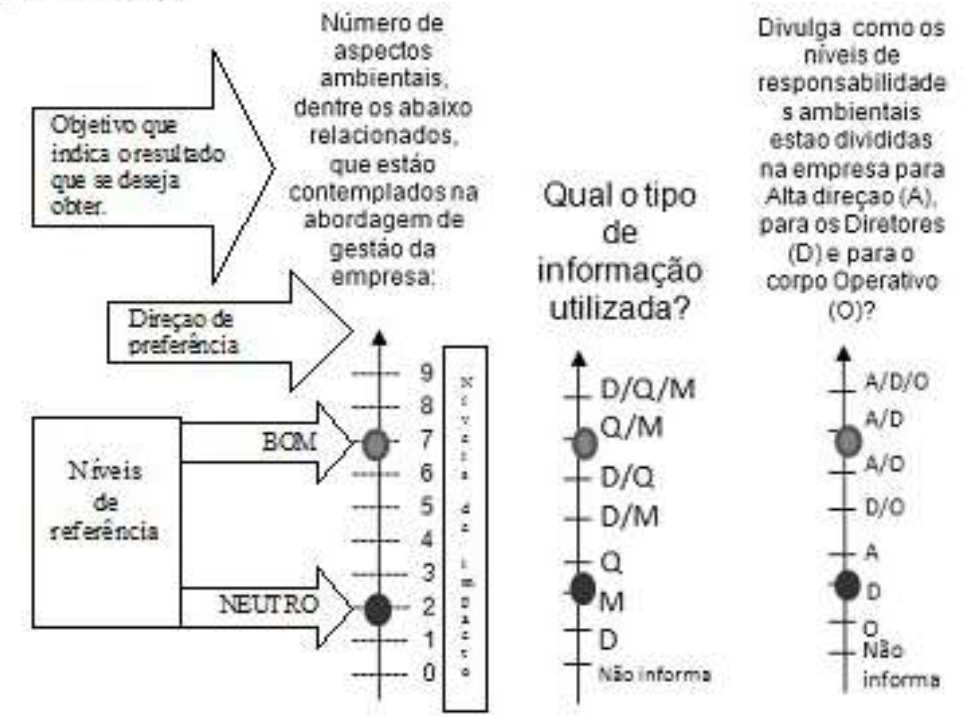

Figura 2: Escalas para medir desempenho (Crespo Soler et al., 2011).

Segundo os estudos de Crespo Soler et al (2011), as escalas ordinais representam o objetivo de cada critério e subcritérios, e mostram a ordenação (direção de preferência) das possíveis ocorrências de desempenho (níveis de impacto) e estabelecimento dos níveis de referência níveis Bom e Neutro. As escalas ordinais são transformadas em cardinais através de um software semântico e expressam o sacrifício ou esforço para passar de um nível para o outro.

Assim, com base no resultado é possível obter um diagnóstico sistêmico da situação, pois há valoração de cada critério, subcritério, cluster, e avaliação global.

\section{Análise dos resultados}

Os resultados da pesquisa estão divididos em cinco partes para análise dos quatro clasters e seus critérios e subcritérios e uma avaliação global do Relatório de Sustentabilidade.

\subsection{Análise docluster "Gestão Ambiental"}

No primeiro clusterdenominado Gestão Ambiental, os critérios avaliados desdobram-se em: Abordagem de gestão (5\%), Objetivos (5\%), Política ambiental(5\%), Responsabilidade profissional (5\%), Treinamento e Conscientização (15\%),Monitoramento e acompanhamento (40\%) e Informações contextuais $(25 \%)$.

Conforme Quadro 2, verifica-se que a empresa informou no escopo dos relatórios os aspectos: material, água, energia, emissões, efluentes, resíduos, produtos/serviços. Não foram mencionados os subcritérios biodiversidade e transporte. A reesponsabilidade profissional pela gestão ambiental está direcionada à alta administração. Os programas de treinamento e conscientização são voltados tanto para o público interno e externo. O monitoramento e acompanhamento divulgado é um ponto forte: apresenta as certifiações nacionacionais (ISO 9001, ISO 14001 e OHSAS 18001) e internacionais (IECQ QC 080.000) e de auditagem dos processos por auditoria interna e externa da empresa. Porém não informou os mesmos dados para a cadeia de suprimentos.

O cluster "gestão ambiental" alcançou64,20 pontos, desempenho considerado "Neutro" pela escala de medição de desempenho. 
REAVI

Universidade do Estado de Santa Catarina

Centro de Educação Superior do Alto Vale do Itajaí

\begin{tabular}{|c|c|c|c|c|c|c|c|c|c|c|c|}
\hline \multirow{2}{*}{$\begin{array}{c}\text { Environmental Disclosure } \\
\text { Assessement - EDE }\end{array}$} & \multirow[t]{2}{*}{ Taxas } & \multirow[t]{2}{*}{ SQ } & \multirow[t]{2}{*}{ Valoração } & \multicolumn{8}{|c|}{ Níve is de impacto - ESCALA ORDINAL } \\
\hline & & & & n1 & n2 & n3 & n4 & n5 & n6 & n7 & n8 \\
\hline 1. Gestão ambiental & $10 \%$ & & 64,20 & & & & & & & & \\
\hline 1.1 Abordagem de gestão & $5 \%$ & $\mathrm{n} 7$ & 85,00 & 0 & 1 & 2 & 3 & 4 & 5 & 6 & 7 \\
\hline 1.2. Obje tivos & $5 \%$ & $\mathrm{n} 7$ & 85,00 & 0 & 1 & 2 & 3 & 4 & 5 & 6 & 7 \\
\hline 1.3. Política ambiental & $5 \%$ & $\mathrm{n} 8$ & 100,00 & 0 & 1 & 2 & 3 & 4 & 5 & 6 & 7 \\
\hline 1.4. Responsabilidade profissional & $5 \%$ & $\mathrm{n} 4$ & 38,00 & NADA & $\mathrm{O}$ & $\mathrm{D}$ & A & $\mathrm{D} / \mathrm{O}$ & $\mathrm{A} / \mathrm{O}$ & $\mathrm{A} / \mathrm{D}$ & $\mathrm{A} / \mathrm{D} / \mathrm{O}$ \\
\hline 1.5. Treinamento e conscientização & $15 \%$ & & 89,74 & & & & & & & & \\
\hline 1.5.1. Programas & $42 \%$ & $\mathrm{n} 3$ & 100,00 & NADAE & $\mathrm{OOU}$ & $\mathrm{I} / \mathrm{E}$ & & & & & \\
\hline 1.5.2. Tipo de informação & $38 \%$ & n6 & 73,00 & NADA & $\mathrm{D}$ & $\mathrm{M}$ & $\mathrm{Q}$ & $\mathrm{D} / \mathrm{M}$ & $\mathrm{D} / \mathrm{Q}$ & $\mathrm{Q} / \mathrm{M}$ & $\mathrm{D} / \mathrm{Q} / \mathrm{M}$ \\
\hline 1.5.3. Periodicidade & $20 \%$ & $\mathrm{n} 3$ & 100,00 & NADA & $\mathrm{E}$ & $\mathrm{A}$ & & & & & \\
\hline $\begin{array}{l}\text { 1.6. Monitoramento e } \\
\text { acomnanhamento }\end{array}$ & $40 \%$ & & 75,84 & & & & & & & & \\
\hline 1.6.1. Empresa & $80 \%$ & & 100,00 & & & & & & & & \\
\hline $\begin{array}{l}\text { 1.6.1.1. Procedimentos de } \\
\text { monitoramento }\end{array}$ & $20 \%$ & $\mathrm{n} 8$ & 100,00 & 0 & 1 & 2 & 3 & 4 & 5 & 6 & 7 \\
\hline $\begin{array}{l}\text { 1.6.1.2. Medidas corretivas e } \\
\text { preditivas }\end{array}$ & $23 \%$ & $\mathrm{n} 8$ & 100,00 & 0 & 1 & 2 & 3 & 4 & 5 & 6 & 7 \\
\hline 1.6.1.3. Certificações & $27 \%$ & $\mathrm{n} 4$ & 100,00 & NADA & $\mathrm{N}$ & $\mathrm{I}$ & $\mathrm{I} / \mathrm{N}$ & & & & \\
\hline 1.6.1.4. Auditoria & $30 \%$ & $\mathrm{n} 4$ & 100,00 & $0 \%$ & $25 \%$ & $50 \%$ & $75 \%$ & $100 \%$ & & & \\
\hline 1.6.2. Cadeia de suprimentos & $20 \%$ & & $-20,78$ & & & & & & & & \\
\hline $\begin{array}{l}\text { 1.6.2.1. Procedimentos de } \\
\text { monitoramento }\end{array}$ & $20 \%$ & $\mathrm{n} 1$ & $-146,00$ & 0 & 1 & 2 & 3 & 4 & 5 & 6 & 7 \\
\hline 1.6.2.2. Medidas corretivas e preditivas & $23 \%$ & $\mathrm{n} 1$ & $-146,00$ & 0 & 1 & 2 & 3 & 4 & 5 & 6 & 7 \\
\hline 1.6.2.3. Certificações & $27 \%$ & $\mathrm{n} 4$ & 100,00 & NADA & $\mathrm{N}$ & $\mathrm{I}$ & $\mathrm{I} / \mathrm{N}$ & & & & \\
\hline 1.6.2.4. Auditoria & $30 \%$ & $\mathrm{n} 3$ & 50,00 & $0 \%$ & $25 \%$ & $50 \%$ & $75 \%$ & $100 \%$ & & & \\
\hline 1.7. Informações contextuais & $25 \%$ & & 20,00 & & & & & & & & \\
\hline 1.7.1. Resultados ou metas & $33 \%$ & $\mathrm{n} 1$ & $-75,00$ & $0 \%$ & $25 \%$ & $50 \%$ & $75 \%$ & $100 \%$ & & & \\
\hline 1.7.2. Riscos e oportunidades & $20 \%$ & $\mathrm{n} 1$ & 0,00 & $\mathrm{NÃO}$ & SIM & & & & & & \\
\hline 1.7.3. Desempenho ambiental & $32 \%$ & $\mathrm{n} 8$ & 100,00 & 0 & 1 & 2 & 3 & 4 & 5 & 6 & 7 \\
\hline 1.7.4. Estratégias & $15 \%$ & $\mathrm{n} 7$ & 85,00 & 0 & 1 & 2 & 3 & 4 & 5 & 6 & 7 \\
\hline
\end{tabular}

( $A=$ Alta Direção, $D=$ Corpo diretivo, $O=$ Equipe operativa; $A=$ Anual, $E=$ Eventual; $D=$ Descritiva, $Q=$ Quantitativa, $M=$ Monetária; $I=$ Internacional, $N=$ Nacional).

Quadro 2: Avaliação da informação ambiental sobre critérios de Gestão Ambiental

\subsection{Análise docluster "Consumo de Recursos Naturais"}

O segundo cluster é denominado Consumo de recursos naturais, e presta informações sobre a avaliação dos seguintes critérios: consumo de materiais (5\%), energia (43\%), água (35\%) e biodiversidade (17\%).

Nas informações relativas aos materiais avaliam-se os tipos (quantidade, descrição e valor) e o \% de materiais utilizados que são reciclados. Para o critério energia, informações segregadas para os tipos de energia direta e indireta, como consumo, economia, eficiência e redução de energia. Para o critério água, retirada por fonte, fontes hídricas significativamente afetadas. Já para o critério biodiversidade, identificação de áreas de alto índice de biodiversidade, inventário de impactos, habitats protegidos ou restaurados, gestão e lista vermelha - áreas afetadas.

$\mathrm{Na}$ avaliação conforme Quadro 3, observa-se que a empresa divulga informações para materiais, energia e água considerada "forte", de forma quantificada monetariamente, descritiva e comparativa com anos anteriores. Dos produtos coletados (compressores) 99\% são reciclados e voltam à cadeia de produção como matéria-prima. Tanto para energia como água, a empresa aponta projeções e metas para os próximos anos, mas não informa o percentual de metas de 


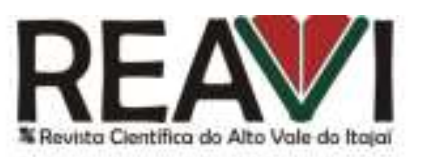

Universidade do Estado de Santa Catarina

Centro de Educação Superior do Alto Vale do Itajaí

redução de consumo de energia alcançadas no último ano em comparação com o ano anterior. O critério biodiversidade não foi mencionado no Relatório da empresa, também auxiliou na redução da valoração deste cluster. 
REAVI

Universidade do Estado de Santa Catarina

Centro de Educação Superior do Alto Vale do Itajaí

\begin{tabular}{|c|c|c|c|c|c|c|c|c|c|c|c|c|c|}
\hline \multirow{2}{*}{\begin{tabular}{|c|} 
Environmental Disclosure Assessement \\
- EDE \\
\end{tabular}} & \multirow[t]{2}{*}{ Taxas } & \multirow[t]{2}{*}{ SQ } & \multirow[t]{2}{*}{ Valoração } & \multicolumn{10}{|c|}{ Níveis de impacto - ESCALA ORDINAL } \\
\hline & & & & n1 & $\mathrm{n} 2$ & n3 & n4 & n5 & n6 & $\mathrm{n} 7$ & n8 & n9 & nx \\
\hline 2. Consumo de recursos naturais & $28 \%$ & & 33,64 & & & & & & & & & & \\
\hline 2.1. Mate riais & $5 \%$ & & 123,05 & & & & & & & & & & \\
\hline 2.1.1. Tipo de materiais & $35 \%$ & n6 & 73,00 & NADA & $\mathrm{D}$ & $\mathrm{M}$ & $\mathrm{Q}$ & $\mathrm{D} / \mathrm{M}$ & $\mathrm{D} / \mathrm{Q}$ & $\mathrm{Q} / \mathrm{M}$ & $\mathrm{D} / \mathrm{Q} / \mathrm{M}$ & & \\
\hline 2.1.2. Reciclados & $65 \%$ & n5 & 150,00 & $0 \%$ & $25 \%$ & $50 \%$ & $75 \%$ & $100 \%$ & & & & & \\
\hline 2.2. Energia & $43 \%$ & & 51,46 & & & & & & & & & & \\
\hline 2.2.1. Energia Direta & $40 \%$ & & 96,55 & & & & & & & & & & \\
\hline 2.2.1.1. Tipo de energia direta & $35 \%$ & $\mathrm{n} 8$ & 118,00 & NADA & $\mathrm{D}$ & $\mathrm{M}$ & $\mathrm{Q}$ & $\mathrm{D} / \mathrm{M}$ & $\mathrm{D} / \mathrm{Q}$ & $\mathrm{Q} / \mathrm{M}$ & $\mathrm{D} / \mathrm{Q} / \mathrm{M}$ & & \\
\hline 2.2.1.2. Gestão de desempenho & $65 \%$ & & 85,00 & & & & & & & & & & \\
\hline 2.2.1.2.1. Sistema métrico & $40 \%$ & $\mathrm{n} 3$ & 50,00 & NADA & $\mathrm{PC}$ & SMI & $\mathrm{SMI}+\mathrm{PC}$ & & & & & & \\
\hline 2.2.1.2.2. Uso de protocolos & $35 \%$ & $\mathrm{n} 2$ & 100,00 & $\mathrm{NÃO}$ & SIM & & & & & & & & \\
\hline 2.2.1.2.3. Tendências & $25 \%$ & n6 & 120,00 & NADA & Outros & $\mathrm{U}$ & U/A & $\mathrm{U} / \mathrm{P}$ & 3 ANOS & & & & \\
\hline 2.2.2. Energia Indireta & $35 \%$ & & 90,25 & & & & & & & & & & \\
\hline 2.2.2.1. Tipo de energia indireta & $35 \%$ & $\mathrm{n} 7$ & 100,00 & NADA & $\mathrm{D}$ & $\mathrm{M}$ & $\mathrm{Q}$ & $\mathrm{D} / \mathrm{M}$ & $\mathrm{D} / \mathrm{Q}$ & $\mathrm{Q} / \mathrm{M}$ & $\mathrm{D} / \mathrm{Q} / \mathrm{M}$ & & \\
\hline 2.2.1.2. Gestão de desempenho & $65 \%$ & & 85,00 & & & & & & & & & & \\
\hline 2.2.1.2.1. Sistema métrico & $40 \%$ & $\mathrm{n} 3$ & 50,00 & NADA & $\mathrm{PC}$ & SMI & $\mathrm{SMI}+\mathrm{PC}$ & & & & & & \\
\hline 2.2.1.2.2. Uso de protocolos & $35 \%$ & $\mathrm{n} 2$ & 100,00 & NÃO & SIM & & & & & & & & \\
\hline 2.2.1.2.3. Tendências & $25 \%$ & n6 & 120,00 & NADA & Outros & $\mathrm{U}$ & U/A & $\mathrm{U} / \mathrm{P}$ & 3 ANOS & & & & \\
\hline 2.2.3. Economia, eficiência e redução & $25 \%$ & & $-75,00$ & & & & & & & & & & \\
\hline 2.2.3.1. Produtos e serviços & $40 \%$ & $\mathrm{n} 1$ & $-75,00$ & $0 \%$ & $25 \%$ & $50 \%$ & $75 \%$ & $100 \%$ & & & & & \\
\hline 2.2.3.2. Economia e redução & $60 \%$ & & $-75,00$ & & & & & & & & & & \\
\hline 2.2.3.2.1. Redução por economia & $50 \%$ & $\mathrm{n} 1$ & $-75,00$ & $0 \%$ & $25 \%$ & $50 \%$ & $75 \%$ & $100 \%$ & & & & & \\
\hline 2.2.3.2.2. Redução por Eficiência & $50 \%$ & $\mathrm{n} 1$ & $-75,00$ & $0 \%$ & $25 \%$ & $50 \%$ & $75 \%$ & $100 \%$ & & & & & \\
\hline 2.3. Água & $35 \%$ & & 37,03 & & & & & & & & & & \\
\hline 2.3.1. Retirada de água por fonte & $50 \%$ & & 96,55 & & & & & & & & & & \\
\hline 2.3.1.1. Tipo de informação & $35 \%$ & $\mathrm{n} 8$ & 118,00 & NADA & $\mathrm{D}$ & $\mathrm{M}$ & $\mathrm{Q}$ & $\mathrm{D} / \mathrm{M}$ & $\mathrm{D} / \mathrm{Q}$ & $\mathrm{Q} / \mathrm{M}$ & $\mathrm{D} / \mathrm{Q} / \mathrm{M}$ & & \\
\hline 2.2.1.2. Gestão de desempenho & $65 \%$ & & 85,00 & & & & & & & & & & \\
\hline 2.2.1.2.1. Sistema métrico & $40 \%$ & $\mathrm{n} 3$ & 50,00 & NADA & $\mathrm{PC}$ & SMI & $\mathrm{SMI}+\mathrm{PC}$ & & & & & & \\
\hline 2.2.1.2.2. Uso de protocolos & $35 \%$ & $\mathrm{n} 2$ & 100,00 & $\mathrm{NÃO}$ & SIM & & & & & & & & \\
\hline 2.2.1.2.3. Tendências & $25 \%$ & n6 & 120,00 & NADA & Outros & $\mathrm{U}$ & U/A & $\mathrm{U} / \mathrm{P}$ & 3 ANOS & & & & \\
\hline 2.3.2. Fontes hídricas signif. afetadas & $35 \%$ & & 0,00 & & & & & & & & & & \\
\hline 2.3.2.1. Volume médio anual & $45 \%$ & $\mathrm{n} 1$ & 0,00 & $\mathrm{NÃO}$ & SIM & & & & & & & & \\
\hline 2.3.2.2. Verificação & $20 \%$ & $\mathrm{n} 1$ & 0,00 & $\mathrm{NÃO}$ & SIM & & & & & & & & \\
\hline 2.3.2.3. Referência & $35 \%$ & $\mathrm{n} 1$ & 0,00 & $\mathrm{NÃO}$ & SIM & & & & & & & & \\
\hline 2.3.3. Água reutilizada e reciclada & $15 \%$ & $\mathrm{n} 1$ & $-75,00$ & $0 \%$ & $25 \%$ & $50 \%$ & $75 \%$ & $100 \%$ & & & & & \\
\hline 2.4. Biodiversidade & $17 \%$ & & $-44,72$ & & & & & & & & & & \\
\hline 2.4.1. Identificação de áreas de alto î́ & $30 \%$ & & $-70,00$ & & & & & & & & & & \\
\hline 2.4.1.1. Área de abrangência & $50 \%$ & $\mathrm{n} 1$ & 0,00 & NÃO & SIM & & & & & & & & \\
\hline 2.4.1.2 Área operacional & $50 \%$ & $\mathrm{n} 1$ & $-140,00$ & 0 & 1 & 2 & 3 & 4 & 5 & $6 \mathrm{ou}+$ & & & \\
\hline 2.4.2. Inventário de impactos & $30 \%$ & & $-39,00$ & & & & & & & & & & \\
\hline 2.4.2.1. Natureza do impacto & $50 \%$ & $\mathrm{n} 1$ & 0,00 & $\mathrm{NÃO}$ & SIM & & & & & & & & \\
\hline 2.4.2.2 Abrangência do impacto & $50 \%$ & $\mathrm{n} 1$ & $-78,00$ & NADA & $\mathrm{D}$ & $\mathrm{I}$ & $\mathrm{R}$ & $\mathrm{D} / \mathrm{I}$ & $\mathrm{D} / \mathrm{R}$ & $\mathrm{I} / \mathrm{R}$ & $\mathrm{D} / \mathrm{I} / \mathrm{R}$ & & \\
\hline 2.4.3. Habitats protegidos ou restaura & $15 \%$ & & $-35,10$ & & & & & & & & & & \\
\hline 2.4.3.1. Tamanho e localização & $45 \%$ & $\mathrm{n} 1$ & $-78,00$ & NADA & $\mathrm{T}$ & $\mathrm{L}$ & $\mathrm{Tm}$ & $\mathrm{T} / \mathrm{L}$ & $\mathrm{T} / \mathrm{Tm}$ & $\mathrm{Tm} / \mathrm{L}$ & $\mathrm{T} / \mathrm{Tm} / \mathrm{L}$ & & \\
\hline 2.4.3.2. Aprovação & $35 \%$ & $\mathrm{n} 1$ & 0,00 & NÃO & SIM & & & & & & & & \\
\hline 2.4.3.3. Parcerias & $20 \%$ & $\mathrm{n} 1$ & 0,00 & NÃO & SIM & & & & & & & & \\
\hline 2.4.4. Gestão da biodiversidade & $15 \%$ & & $-45,00$ & & & & & & & & & & \\
\hline 2.4.4.1. Regulamentos & $35 \%$ & $\mathrm{n} 1$ & 0,00 & NÃO & SIM & & & & & & & & \\
\hline 2.4.4.2. Política sobre biodiversidade & $45 \%$ & $\mathrm{n} 1$ & $-100,00$ & 0 & 1 & 2 & 3 & 4 & 5 & & & & \\
\hline 2.4.4.3. Gestão de riscos & $20 \%$ & $\mathrm{n} 1$ & 0,00 & NÃO & SIM & & & & & & & & \\
\hline 2.4.5. Lista vermelha & $10 \%$ & & 0,00 & & & & & & & & & & \\
\hline 2.4.5.1. Localização & $50 \%$ & $\mathrm{n} 1$ & 0,00 & NADA & NAC & IUCN & $\mathrm{AC}+\mathrm{IUC}$ & & & & & & \\
\hline 2.4.5.2. Espécies ameaçadas & $50 \%$ & $\mathrm{n} 1$ & 0,00 & NADA & Q & Ex & $\mathrm{Q}+\mathrm{Ex}$ & & & & & & \\
\hline
\end{tabular}

$D-M-Q$ (Descritivo, Monetário, Quantitativo), SMI-PC (Sistema Métrico Internacional, Padrões de Conversão),

U/P - U/A - U(Último/Penúltimo Ano, Último e Ano Anterior; Ultimo ano), A/I (Ações - Iniciativas)

Quadro 3: Avaliação da informação ambiental critérios de Consumo de Recursos Naturais

O segundo cluster "Consumo de Recursos Naturais"alcançou valoração de 33,64 pontos, 


\section{REAVI}

desempenho considerado moderado.
Universidade do Estado de Santa Catarina

Centro de Educação Superior do Alto Vale do Itajaí

\subsection{Análise da cluster "Emissões, Efluentes líquidos, Resíduos, Produtos/Serviços e Transporte"}

O terceiro cluster avalia os critérios Emissões (35\%), Efluentes Líquidos (15\%), Resíduos (30\%), Produtos/ Serviços (8\%) e Transporte (12\%).

Nas emissões, são avaliadas as informações das emissões diretas e indiretas, emissões de substâncias destruidoras da camada de ozônio, emissões de Nox, Sox e outras substâncias e redução de emissões. Para os efluentes, o tipo de informação, tratamento e percentual tratado e metas anuais. No subcritério resíduos, informações acerca dos resíduos sólidos, resíduos perigosos transportados e metas de redução. Para o subcritério Produtos e serviços avalia os impactos e recuperação de descartes. Já para transportes, os impactos dos transportes, critérios de avaliação de impactos (tipo e meta), conforme Quadro 4.

A empresa avaliada apresentou informações com valoração considerada boa para o cluster em geral. São pontos positivos as informações descritivas, monetárias e quantitativas e nas unidades de medida internacionais para emissões, efluentes líquidos, resíduos perigosos e não perigosos, que de forma global vem gerando menos resíduos e reciclando mais, $96 \%$ dos resíduos são reciclados segundo o relatório. Como pontos negativos, as informações para os subcritérios redução de emissões que não foi informado e metas, pois a empresa não vislumbrou as metas alcançadas referentes ao ano anterior, apesar de apresentar metas para o futuro.

Este cluster alcançou a pontuação 39,03, desempenho considerado "moderado". 
REAVI

\begin{tabular}{|c|c|c|c|c|c|c|c|c|c|c|c|}
\hline \multirow{2}{*}{$\begin{array}{l}\text { Environmental Disclosure } \\
\text { Assessement - EDE }\end{array}$} & \multirow[t]{2}{*}{ Taxas } & \multirow[t]{2}{*}{ SQ } & \multirow[t]{2}{*}{ Valoraçãd } & \multicolumn{8}{|c|}{ Níveis de impacto - ESCALA ORDINAL } \\
\hline & & & & n1 & n2 & n3 & n4 & n5 & n6 & $\mathrm{n} 7$ & n8 \\
\hline 3. Emissões, efluentes, resíduos e imp: & $45 \%$ & & 39,03 & & & & & & & & \\
\hline 3.1. Emissões & $35 \%$ & & 123,05 & & & & & & & & \\
\hline 3.1.1. Emissões diretas & $30 \%$ & & 73,00 & & & & & & & & \\
\hline 3.3.1.1. Tipo de informação & $35 \%$ & $\mathrm{n} 4$ & 150,00 & NADA & $\mathrm{D}$ & $\mathrm{M}$ & $\mathrm{Q}$ & $\mathrm{D} / \mathrm{M}$ & $\mathrm{D} / \mathrm{Q}$ & $\mathrm{Q} / \mathrm{M}$ & $\mathrm{D} / \mathrm{Q} / \mathrm{M}$ \\
\hline 3.2.1.2. Gestão de desempenho & $65 \%$ & & 51,46 & & & & & & & & \\
\hline 3.2.1.2.1. Sistema métrico & $40 \%$ & $\mathrm{n} 3$ & 96,55 & NADA & $\mathrm{PC}$ & SMI & $\mathrm{MI}+\mathrm{PC}$ & & & & \\
\hline 3.2.1.2.2. Uso de protocolos & $35 \%$ & $\mathrm{n} 2$ & 118,00 & NÃO & SIM & & & & & & \\
\hline 3.2.1.2.3. Tendências & $25 \%$ & $\mathrm{n} 5$ & 85,00 & NADA & Outros & $\mathrm{U}$ & U/A & $\mathrm{U} / \mathrm{P}$ & BANOS & & \\
\hline 3.1.2. Emissões indiretas & $28 \%$ & & 50,00 & & & & & & & & \\
\hline 3.3.1.1. Tipo de informação & $35 \%$ & $\mathrm{n} 8$ & 100,00 & NADA & $\mathrm{D}$ & $\mathrm{M}$ & $\mathrm{Q}$ & $\mathrm{D} / \mathrm{M}$ & $\mathrm{D} / \mathrm{Q}$ & $\mathrm{Q} / \mathrm{M}$ & $\mathrm{D} / \mathrm{Q} / \mathrm{M}$ \\
\hline 3.2.1.2. Gestão de desempenho & $65 \%$ & & 120,00 & & & & & & & & \\
\hline 3.2.1.2.1. Sistema métrico & $40 \%$ & $\mathrm{n} 3$ & 90,25 & NADA & PC & SMI & $\mathrm{MI}+\mathrm{PC}$ & & & & \\
\hline 3.2.1.2.2. Uso de protocolos & $35 \%$ & $\mathrm{n} 2$ & 100,00 & NÃO & SIM & & & & & & \\
\hline 3.2.1.2.3. Tendências & $25 \%$ & $\mathrm{n} 5$ & 85,00 & NADA & Outros & $\mathrm{U}$ & U/A & $\mathrm{U} / \mathrm{P}$ & 3 ANOS & & \\
\hline $\begin{array}{l}\text { 3.1.3. Emissões } \\
\text { destruidoras de } \mathrm{c}\end{array}$ & $15 \%$ & $\mathrm{n} 1$ & 50,00 & NÃO & SIM & & & & & & \\
\hline $\begin{array}{l}\text { 3.1.4. Emi } \\
\text { substância }\end{array}$ & $15 \%$ & $\mathrm{n} 1$ & 100,00 & NÃO & SIM & & & & & & \\
\hline 3.1.5. Redução c & $12 \%$ & & 120,00 & & & & & & & & \\
\hline 3.1.5.1. Tipo de informação & $30 \%$ & $\mathrm{n} 1$ & $-75,00$ & NADA & $\mathrm{D}$ & $\mathrm{M}$ & $\mathrm{Q}$ & $\mathrm{D} / \mathrm{M}$ & $\mathrm{D} / \mathrm{Q}$ & $\mathrm{Q} / \mathrm{M}$ & $\mathrm{D} / \mathrm{Q} / \mathrm{M}$ \\
\hline 3.1.5.2. Ocorrência & $30 \%$ & $\mathrm{n} 1$ & $-75,00$ & NADA & A & $\mathrm{I}$ & $\mathrm{A} / \mathrm{I}$ & & & & \\
\hline 3.1.5.3 Tendências & $40 \%$ & $\mathrm{n} 4$ & $-75,00$ & NADA & Outros & $\mathrm{U}$ & U/A & $\mathrm{U} / \mathrm{P}$ & BANOS & & \\
\hline 3.2. Efluentes líquidos & $15 \%$ & & $-75,00$ & & & & & & & & \\
\hline 3.2.1. Tipo de informação & $30 \%$ & $\mathrm{n} 8$ & $-75,00$ & NADA & $\mathrm{D}$ & $\mathrm{M}$ & $\mathrm{Q}$ & $\mathrm{D} / \mathrm{M}$ & $\mathrm{D} / \mathrm{Q}$ & $\mathrm{Q} / \mathrm{M}$ & $\mathrm{D} / \mathrm{Q} / \mathrm{M}$ \\
\hline 3.2.2. Tratamento & $40 \%$ & & 37,03 & & & & & & & & \\
\hline 3.2.2.1. \% Tratado & $65 \%$ & $\mathrm{n} 2$ & 96,55 & $0 \%$ & $25 \%$ & $50 \%$ & $75 \%$ & $100 \%$ & & & \\
\hline 3.2.2.2 Método de Tratamento & $35 \%$ & $\mathrm{n} 2$ & 118,00 & NÃO & SIM & & & & & & \\
\hline 3.2.3. Metas anuais & $30 \%$ & $\mathrm{n} 1$ & 85,00 & $0 \%$ & $25 \%$ & $50 \%$ & $75 \%$ & $100 \%$ & & & \\
\hline 3.3. Resíduos & 30\% & & $\mathbf{5 0 , 0 0}$ & & & & & & & & \\
\hline 3.3.1. Resíduos sólidos & $35 \%$ & & 100,00 & & & & & & & & \\
\hline 3.3.1.1. Tipo de informação & $50 \%$ & n6 & 120,00 & NADA & $\mathrm{D}$ & $\mathrm{M}$ & $\mathrm{Q}$ & $\mathrm{D} / \mathrm{M}$ & $\mathrm{D} / \mathrm{Q}$ & $\mathrm{Q} / \mathrm{M}$ & $\mathrm{D} / \mathrm{Q} / \mathrm{M}$ \\
\hline 3.3.1.2 Método de disposição & $50 \%$ & $\mathrm{n} 2$ & 0,00 & NÃO & SIM & & & & & & \\
\hline 3.3.2. Resíduos perigosos transportados & $35 \%$ & & 0,00 & & & & & & & & \\
\hline 3.3.2.1. Tipo de informação & $50 \%$ & n6 & 0,00 & NADA & $\mathrm{D}$ & $\mathrm{M}$ & $\mathrm{Q}$ & $\mathrm{D} / \mathrm{M}$ & $\mathrm{D} / \mathrm{Q}$ & $\mathrm{Q} / \mathrm{M}$ & $\mathrm{D} / \mathrm{Q} / \mathrm{M}$ \\
\hline 3.3.2.2 Tratamento & $50 \%$ & $\mathrm{n} 2$ & 0,00 & NÃO & SIM & & & & & & \\
\hline 3.3.3. Metas de redução & $30 \%$ & $\mathrm{n} 1$ & $-75,00$ & $0 \%$ & $25 \%$ & $50 \%$ & $75 \%$ & $100 \%$ & & & \\
\hline 3.4. Produtos e serviços & $8 \%$ & & $-44,72$ & & & & & & & & \\
\hline 3.4.1. Impactos & $65 \%$ & & $-70,00$ & & & & & & & & \\
\hline 3.4.1.1. Iniciativas & $50 \%$ & n6 & 0,00 & 0 & 1 & 2 & 3 & 4 & 5 & $6 \mathrm{ou}+$ & \\
\hline 3.4.1.2. Redução de Impactos & $50 \%$ & n6 & $-140,00$ & 0 & 1 & 2 & 3 & 4 & 5 & $6 \mathrm{ou}+$ & \\
\hline 3.4.2. Recuperação de descartes & $35 \%$ & & $-39,00$ & & & & & & & & \\
\hline 3.4.2.1. Quantidade & $50 \%$ & $\mathrm{n} 2$ & 0,00 & NÃO & SIM ou & NA & & & & & \\
\hline 3.4.2.2. Categoria & $50 \%$ & $\mathrm{n} 2$ & $-78,00$ & NÃO & SIM ou & NA & & & & & \\
\hline 3.5.Transporte & $12 \%$ & & $-35,10$ & & & & & & & & \\
\hline 3.5.1. Impactos dos transportes & $45 \%$ & & $-78,00$ & & & & & & & & \\
\hline 35.1.1. Transportes utilizados pela emp & $50 \%$ & & 0,00 & & & & & & & & \\
\hline 3.5.1.1.1 Tipo de informação & $50 \%$ & $\mathrm{n} 2$ & 0,00 & NADA & $\mathrm{D}$ & $\mathrm{M}$ & $\mathrm{Q}$ & $\mathrm{D} / \mathrm{M}$ & $\mathrm{D} / \mathrm{Q}$ & $\mathrm{Q} / \mathrm{M} \mathrm{I}$ & $\mathrm{D} / \mathrm{Q} / \mathrm{M}$ \\
\hline 3.5.1.1.2. Abrangência & $50 \%$ & $\mathrm{n} 2$ & $-45,00$ & NÃO & SIM & & & & & & \\
\hline $\begin{array}{l}\text { 3.5.1.2. Transportes utilizados para fins } \\
\text { logísticos }\end{array}$ & $28 \%$ & $\mathrm{n} 2$ & 0,00 & NÃO & SIM & & & & & & \\
\hline $\begin{array}{l}\text { 3.5.1.3. Transportes utilizados para } \\
\text { transporte do público interno }\end{array}$ & $22 \%$ & $\mathrm{n} 1$ & $-100,00$ & NÃO & SIM & & & & & & \\
\hline 3.5.2. Critérios de avaliação de impactos & $20 \%$ & $\mathrm{n} 1$ & 0,00 & NÃO & SIM & & & & & & \\
\hline 3.5.3 Redução de impacto & $35 \%$ & & 0,00 & & & & & & & & \\
\hline 3.5.3.1. Tipo & $35 \%$ & $\mathrm{n} 1$ & 0,00 & NÃO & SIM & & & & & & \\
\hline 3.5.3.2. Meta & $65 \%$ & $\mathrm{n} 1$ & 0,00 & $0 \%$ & $25 \%$ & $50 \%$ & $75 \%$ & $100 \%$ & & & \\
\hline
\end{tabular}

Universidade do Estado de Santa Catarina

Centro de Educação Superior do Alto Vale do Itajaí 


\section{REAVI}

Universidade do Estado de Santa Catarina

Centro de Educação Superior do Alto Vale do Itajaí

D-M-Q (Descritivo, Monetário, Quantitativo), SMI-PC (Sistema Métrico Internacional, Padrões de Conversão), U/P - U/A - U(Último/Penúltimo Ano, Último e Ano Anterior; Ultimo ano), A/I (Ações - Iniciativas)

Quadro 3: Avaliação da informação ambiental sobre critérios de emissões, efluentes líquidos, resíduos, produtos/ serviços e transporte

\subsection{Análise docluster "Conformidade Legal e Aspectos Financeiros"}

Neste último cluster são avaliados os critérios conformidade legal (40\%) e aspectos financeiros (60\%). Na conformidade legal, os subcritérios avaliados são as sansõe administrativas ou judiciais, multas, sansões não-monetárias e não-conformidades de forma descritiva, monetária e quantitativa.

Para o critério aspectos financeiros a análise está dividida nos subcritérios: reparar, previnir e proteger, devendo ser informadas as contas e valores.

Neste cluster de modo geral a empresa está com uma valoração negativa de $-11,18$, considerada "muito fraca", pois não informou a maioria dos subcritérios, exceto para reparar (resíduos) e previnir (educação e treinamento e certificação externa).

\begin{tabular}{|c|c|c|c|c|c|c|c|c|c|c|c|}
\hline \multirow{2}{*}{$\begin{array}{c}\text { Environmental Disclosure Assessement - } \\
\text { EDE }\end{array}$} & \multirow[t]{2}{*}{ Taxas } & \multirow[t]{2}{*}{ SQ } & \multirow[t]{2}{*}{ Valoraçã } & \multicolumn{8}{|c|}{ Níve is de impacto - ESCALA ORDINAL } \\
\hline & & & & n1 & n2 & n3 & n4 & n5 & n6 & n7 & n8 \\
\hline 4. Conformidade Legal e Aspectos Financeiro & $17 \%$ & & $-11,18$ & & & & & & & & \\
\hline 4.1. Conformidade Legal & $40 \%$ & & $-78,00$ & & & & & & & & \\
\hline 4.1.1. Sanções administrativas ou judiciais & $30 \%$ & $\mathrm{n} 1$ & $-78,00$ & NADA & $\mathrm{D}$ & $\mathrm{M}$ & $\mathrm{Q}$ & $\mathrm{D} / \mathrm{M}$ & $\mathrm{D} / \mathrm{Q}$ & $\mathrm{Q} / \mathrm{M}$ & $\mathrm{D} / \mathrm{Q} / \mathrm{M}$ \\
\hline 4.1.2. Multas & $30 \%$ & $\mathrm{n} 1$ & $-78,00$ & NADA & $\mathrm{D}$ & $\mathrm{M}$ & $\mathrm{Q}$ & $\mathrm{D} / \mathrm{M}$ & $\mathrm{D} / \mathrm{Q}$ & $\mathrm{Q} / \mathrm{M}$ & $\mathrm{D} / \mathrm{Q} / \mathrm{M}$ \\
\hline 4.1.3. Sanções não-monetárias & $20 \%$ & $\mathrm{n} 1$ & $-78,00$ & NADA & $\mathrm{D}$ & $\mathrm{M}$ & $\mathrm{Q}$ & $\mathrm{D} / \mathrm{M}$ & $\mathrm{D} / \mathrm{Q}$ & $\mathrm{Q} / \mathrm{M}$ & $\mathrm{D} / \mathrm{Q} / \mathrm{M}$ \\
\hline 4.1.4. Não-conformidade & $20 \%$ & $\mathrm{n} 1$ & $-78,00$ & NADA & $\mathrm{D}$ & $\mathrm{M}$ & $\mathrm{Q}$ & $\mathrm{D} / \mathrm{M}$ & $\mathrm{D} / \mathrm{Q}$ & $\mathrm{Q} / \mathrm{M}$ & $\mathrm{D} / \mathrm{Q} / \mathrm{M}$ \\
\hline 4.2. Aspectos financeiros & $60 \%$ & & 33,36 & & & & & & & & \\
\hline 4.2.1. Reparar & $48 \%$ & & 20,00 & & & & & & & & \\
\hline 4.2.1.1. Resíduos & $20 \%$ & $\mathrm{n} 2$ & 100,00 & NÃO & SIM & & & & & & \\
\hline 4.2.1.2. Emissões & $20 \%$ & & 0,00 & & & & & & & & \\
\hline 4.2.1.2.1. Tratamento & $50 \%$ & $\mathrm{n} 1$ & 0,00 & NÃO & SIM & & & & & & \\
\hline 4.2.1.2.2. Certificado de emissão & $50 \%$ & $\mathrm{n} 1$ & 0,00 & NÃO & SIM & & & & & & \\
\hline 4.2.1.3. Depreciação e manutenção de equip. & $20 \%$ & $\mathrm{n} 1$ & 0,00 & NÃO & SIM & & & & & & \\
\hline 4.2.1.4. Seguro ambiental & $20 \%$ & $\mathrm{n} 1$ & 0,00 & NÃO & SIM & & & & & & \\
\hline 4.2.1.5. Derramamentos & $20 \%$ & $\mathrm{n} 1$ & 0,00 & NÃO & SIM & & & & & & \\
\hline 4.2.2. Prevenir & $32 \%$ & & 43,00 & & & & & & & & \\
\hline 4.2.2.1. Educação e treinamento & $19 \%$ & $\mathrm{n} 2$ & 100,00 & NÃO & SIM & & & & & & \\
\hline 4.2.2.2. Serviços externos de gestão ambiental & $18 \%$ & $\mathrm{n} 1$ & 0,00 & NÃO & SIM & & & & & & \\
\hline 4.2.2.3. Certificação externa & $17 \%$ & $\mathrm{n} 2$ & 100,00 & NÃO & SIM & & & & & & \\
\hline 4.2.2.4. Serviços gerais de gestão ambiental & $15 \%$ & $\mathrm{n} 1$ & 0,00 & NÃO & SIM & & & & & & \\
\hline 4.2.2.5. Despesas com tecnologias mais limpas & $13 \%$ & $\mathrm{n} 1$ & 0,00 & NÃO & SIM & & & & & & \\
\hline 4.2.2.6. Compras verdes & $11 \%$ & $\mathrm{n} 1$ & 0,00 & NÃO & SIM & & & & & & \\
\hline 4.2.2.7. Outros custos de gestão ambiental & $7 \%$ & $\mathrm{n} 2$ & 100,00 & NÃO & SIM & & & & & & \\
\hline 4.2.3. Proteger & $20 \%$ & & 50,00 & & & & & & & & \\
\hline 4.2.3.1. Disposição de resíduos tratamento & $50 \%$ & $\mathrm{n} 2$ & 100,00 & NÃO & SIM & & & & & & \\
\hline 4.2.3.2. Gestão ambiental & $50 \%$ & $\mathrm{n} 1$ & 0,00 & NÃO & SIM & & & & & & \\
\hline
\end{tabular}

$D-M-Q$ (Descritivo, Monetário, Quantitativo).

Quadro 4: Avaliação da conformidade legal e aspectos financeiros

\subsection{Análise global}

Os pontos fortes e fracos da avaliação da evidenciação da empresa de compressores analisada encontram-se compiladas no Quadro 5. Como pontos fortes pode-se apontar o comprometimento com a gestao ambiental $(72,70)$, os critérios materiais, energia e água do clusterconsumo de recursos naturais; emissões $(123,05)$ e resíduos $(50,00)$. Os pontos fracos estão com os critérios 


\section{REAVI}

Universidade do Estado de Santa Catarina

Centro de Educação Superior do Alto Vale do Itajaí

de biodiversidade $(-44,72)$, efluentes líquidos $(-75,00)$, produtos e serviços $(-44,72)$, transporte ($35,10)$ e conformidade legal $(-78,00)$.

\begin{tabular}{|l|r|r|}
\hline \multicolumn{1}{|c|}{$\begin{array}{c}\text { Environmental Disclosure } \\
\text { Assessement - EDE }\end{array}$} & \multicolumn{1}{c|}{ Taxas } & \multicolumn{1}{c|}{ Valoração } \\
\cline { 2 - 3 } & & \multicolumn{1}{c|}{$\mathbf{3 1 , 2 3}$} \\
\hline 1. Gestão ambiental & $\mathbf{1 0 \%}$ & $\mathbf{6 4 , 2 0}$ \\
\hline 1.1 Abordagem de gestão & $5 \%$ & 85,00 \\
\hline 1.2. Objetivos & $5 \%$ & 85,00 \\
\hline 1.3. Política ambiental & $5 \%$ & 100,00 \\
\hline 1.4. Responsabilidade profissional & $5 \%$ & 38,00 \\
\hline 1.5. Treinamento e conscientização & $15 \%$ & 89,74 \\
\hline 1.6. Monitoramento e acompanhamento & $40 \%$ & 75,84 \\
\hline 1.7. Informações contextuais & $25 \%$ & 20,00 \\
\hline 2. Consumo de recursos naturais & $\mathbf{2 8 \%}$ & $\mathbf{3 3 , 6 4}$ \\
\hline 2.1. Materiais & $5 \%$ & 123,05 \\
\hline 2.2. Energia & $43 \%$ & 51,46 \\
\hline 2.3. Água & $35 \%$ & 37,03 \\
\hline 2.4. Biodiversidade & $17 \%$ & $-44,72$ \\
\hline 3. Emissões, efluentes, resíduos e & & \\
impactos & $\mathbf{4 5 \%}$ & $\mathbf{3 9 , 0 3}$ \\
\hline 3.1. Emissões & $35 \%$ & 123,05 \\
\hline 3.2. Efluentes líquidos & $15 \%$ & $-75,00$ \\
\hline 3.3. Resíduos & $30 \%$ & 50,00 \\
\hline 3.4. Produtos e serviços & $8 \%$ & $-44,72$ \\
\hline 3.5.Transporte & $12 \%$ & $-35,10$ \\
\hline 4. Conformidade Legal e Aspectos & & \\
Financeiros & $\mathbf{1 7 \%}$ & $\mathbf{- 1 1 , 1 8}$ \\
\hline 4.1. Conformidade Legal & $40 \%$ & $-78,00$ \\
\hline 4.2. Aspectos financeiros & $60 \%$ & 33,36 \\
\hline
\end{tabular}

Quadro 5: Avaliação global

Assim, na análise global a avaliação alcançou uma valoração de 31,23 pontos, considerada como desempenho "moderado".

\section{Conclusões}

Este estudo objetivou analisar a evidenciação ambiental de uma empresa do setor industrialcatarinense considerada potencialmente poluidora utilizando-se de uma ferramenta de avaliação de desempenho baseado no GRI e criado a partir da Metodologia Multicritério de Apoio a Decisão Construtivista (MCDA-C) denominado Environmental Disclosure Evaluation (EDE).

O desempenho global alcançado pela empresa por meio da aplicação do modelo EDE de avaliação da evidenciação ambiental foi de 31,23 pontos, o que significa desempenho "moderado" na escala de julgamentos que vai de extremo, muito forte, forte, moderado, fraco, muito fraco e nulo.O estudo demonstrou um maior comprometimento da empresa com a evidenciação de suas informações para as áreas de gestão ambiental, consumo de recursos naturais e emissão e resíduos. Alguns critérios como efluentes líquidos, produtos e transporte, no entanto, carecem de informações mais completas. Os itens com os piores resultados alcançados, ou seja, desempenho "nulo" devido à total falta de informações foram: critério da biodiversidade e o critério conformidade legal que abrange informações como multas, sansões administrativas ou judiciais, sansões não monetárias e não conformidades, bem indicação monetária de aspectos financeiros. 


\section{REAVI}

Universidade do Estado de Santa Catarina

Centro de Educação Superior do Alto Vale do Itajaí

Conclui-se que a empresa mostra-se parcialmente comprometida com a divulgação das informações de caráter ambiental divulgadas em seu relatório de sustentabilidade e apresenta umdesempenho considerado "moderado" na escala de julgamento dos critérios avaliados pelo modelo EDE.

Este estudo limitou-se a realizar um estudo de caso, sugere-se para pesquisas posteriores: (i) estudo de multicascos; (ii) ampliar o período de análise do relatório de sustentabilidade para avaliar a evolução das informações.

\section{Referências}

BELLEN, H. M. VAN. Indicadores de sustentabilidade: uma análise comparativa. 1st ed. Rio de Janeiro: FGV, 2005.

BEUREN, I. M.; BOFF, M. L.; HORN, J. E.; HORN, M. A. Adequação da Evidenciação Social das Empresas de Capital Aberto no Relatório da Administração e Notas Explicativas às Recomendações da NBC T 15. RCO - Revista de Contabilidade e Organizações, v. 4, n. 8, p. 47-68, 2010.

BORGES, F. H.; TACHIBANA, W. K. A evolução da preocupação ambiental e seus reflexos no ambiente dos negócios : uma abordagem histórica. In: XII Simpep. Anais... p.5235-5242, 2005. Bauru.

BRAGA, C. Contabilidade ambiental: ferramenta para a gestão da sustentabilidade. São Paulo (SP): Atlas, 2007.

BRASIL. Lei $n^{\circ} .10 .165$, de 27 de Dezembro de 2000. Dispõe sobre a Política Nacional do Meio Ambiente, seus fins e mecanismos de formulação e aplicação, e dá outras providências. Diário Oficial [da] República Federativa do Brasil. Brasília-DF. Disponível em: http://www.planalto.gov.br/ccivil_03/leis/L10165.htm. Acesso em: 10/07/ 2012.

CALIXTO, L. Uma análise da evidenciação ambiental de companhias brasileiras - de 1997 a 2005. Contabilidade, Gestão e Governança, v. 10, n. 1, 2009.

CORTEZ, R. C.; BELLEN, H. M. VAN; ZARO, E. S. Ferramentas de Responsabilidade Social: uma análise comparativa a partir das dimensões e modelos de RSC. XXXVIII Encontro da ANPAD. Anais... p.1-16, 2014. Rio de Janeiro.

CRESPO, C. S., RIPOLL, V.F., ROSA, F. S., LUNKES, R.J. Modelo Edeenvironmentaldisclosure evaluation. Resultados de pesquisa. Valencia: Quaderns de treball. Facultad de

Economía.Universitat de Valencia, 2011.

DAUB, C.-H. Assessing the quality of sustainability reporting: an alternative methodological approach. Journal of Cleaner Production, v. 15, p. 75-85, 2007. Disponível em: <http://linkinghub.elsevier.com/retrieve/pii/S0959652605001915>. Acesso em: 29/03/2014.

ELKINGTON, J. Governance for Sustainability. Corporate Governance, v. 14, n. 6, p. 522529, 2006.

ENSSLIN, L.; DUTRA, A.; ENSSLIN, S.R. MCDA: A constructivist approach the management of human resources at a governmental agency. International Transactions in Operational Research. n. 7, p. 79-100, 2000.

ENSSLIN, L.; MONTIBELLER, G.N.; e NORONHA, S.M. Apoio à decisão: metodologia para estruturação de problemas e avaliação multicritério de alternativas. Florianópolis: Insular, 2001 


\section{REAVI}

Universidade do Estado de Santa Catarina

Centro de Educação Superior do Alto Vale do Itajaí

GIL, Antonio Carlos. Métodos e técnicas de pesquisa social. 4. ed. São Paulo: Atlas, 1995.

GRI - GLOBAL REPORTING INITIATIVE. Sustainability Reporting Guidelines. Version

3.1. Amsterdam, 2011.

GRI - GLOBAL REPORTING INITIATIVE. WHAT IS GRI? Disponível em: <https://www.globalreporting.org/information/about-gri/what-is-GRI/Pages/default.aspx>.

Acesso em: 21/06/2014a.

GURVITSH, N.; SIDOROVA, I. Survey of Sustainability Reporting Integrated into Annual Reports of Estonian Companies for the years 2007-2010: Based on Companies Listed on Tallinn Stock Exchange as of October 2011. Procedia Economics and Finance, v. 2, p. 26-34, 2012. Disponível em: <http://linkinghub.elsevier.com/retrieve/pii/S2212567112000615>. Acesso em: 27/07/2014.

INSTITUTO BRASILEIRO DE GOVERNANÇA CORPORATIVA. Código das melhores práticas de governança corporativa. 4.ed. 2009. Disponível em: 〈http://www.ibgc.org.br./>. Acesso em: 10/07/2014.

INTERNATIONAL FEDERATION OF ACCOUNTANTS (IFAC). Sustainability Framework 2.0. New York: International Federation of Accountants (IFAC), 2011.

KPMG. KPMG International Survey of Corporate Responsibility Reporting 2005. Amsterdam, 2005.

KPMG. KPMG International Survey of Corporate Responsibility Reporting 2008. Amsterdam, 2008.

KPMG. KPMG International Responsibility Reporting 2011. Amsterdam, 2011.

NASCIMENTO, E. P. DO. Trajetória da sustentabilidade: do ambiental ao social, do social ao econômico. Estudos Avançados, v. 26, n. 74, p. 51-64, 2012.

NIKOLAEVA, R.; BICHO, M. The role of institutional and reputational factors in the voluntary adoption of corporate social responsibility reporting standards. Journal of the Academy of Marketing Science, v. 39, p. 136-157, 2011. Disponível em: <http://link.springer.com/10.1007/s11747-010-0214-5>. Acesso em: 13/07/2014.

OWEN, G. Integrated Reporting: A Review of Developments and their Implications for the Accounting Curriculum. Accounting Education, v. 22, n. 4, p. 340-356, 2013. Disponível em: <http://www.tandfonline.com/doi/abs/10.1080/09639284.2013.817798>.Acesso em: 11/02/2014.

RICHARDSON, R. J. Pesquisa social: métodos e técnicas. 3. ed. São Paulo: Atlas, 2008.

ROSA, F., COSTA, G., PIFITSCHER, E., LUNKES, R.. Termômetro Ambiental: um estudo sobre níveis de comprometimento e desempenho da gestão ambiental em uma empresa do setor fabril do estado de Santa Catarina.AmbienteContábil, v.4. n. 2, p. 18-39, jul/dez. 2012.

SCHALTEGGER, S.; BURRITT, R. L. Sustainability accounting for companies: Catchphrase or decision support for business leaders? Journal of World Business, v. 45, n. 4, p. 375-384, 2010. Centre for Sustainability Management (CSM), Leuphana University of Lueneburg,

Scharnhorststr. 1, 21335 Lueneburg, Germany. Disponível em:

<http://www.scopus.com/inward/record.url?eid=2-s2.0-

77956463638\&partnerID=40\&md5=f9dee95faa7c5b25bee73571e83c5723>. . 


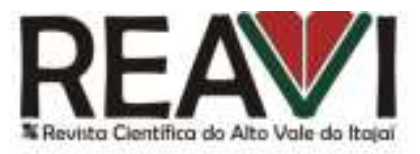

Universidade do Estado de Santa Catarina

Centro de Educação Superior do Alto Vale do Itajaí

SOARES, S. V.; SILVEIRA, E. D. DA; PFITSCHER, E. D.; SIRIDAKIS, C. Informações Ambientais em notas explicativas das empresas dos programas "Novo Mercado" e "Em boa Companhia" da BM\&F BOVESPA. Revista de Contabilidade do Mestrado em Ciências Contábeis da UERJ (online), v. 17, n. Ed. Especial, p. 70-82, 2012.

TINOCO, J. E. P. .; KRAEMER, M. E. P. Contabilidade e gestão ambiental. São Paulo (SP): Atlas, 2004.

YIN, R.K. Estudo de Caso: Planejamento e métodos. 3. ed. Tradução Daniel Grassi. Porto Alegre: Bookman, 2005. 